\title{
FAKTOR-FAKTOR PENYEBAB KEMATIAN BAHASA
}

\author{
Irwan \\ Program Studi Tadris Bahasa Inggris STAIN Batusangkar \\ Korespondensi: J1. Sudirman, No.137. Limakaum, Batusangkar \\ Email: palkot35@yahoo.com)
}

\begin{abstract}
This article discusses about the factors which may cause language death or language dissappear. Based on some linguists' research there are several factors that might cause the death of the language. They are: natural disaster, war and ethnic clearance, epidemic sickness, hegemony of a foreign language, inferior of language sense, migration, political decision, and intercultural marriage problem. In this article the writer would like to anlayze each point of the factors above. The conclusion is a language is like other human life; born, live, develop, lying up and death. This phenomenon is called survival of the fittest; the majority language will hit the minority language along its life.
\end{abstract}

Kata kunci: faktor, kematian, bahasa, dissappear

\section{PENDAHULUAN}

$\mathrm{P}$ ersoalan kematian tidak hanya dialami oleh seluruh makhluk yang bernyawa saja seperti manusia, binatang dan tumbuh-tumbuhan akan tetapi kematian juga dialami oleh bahasa. Istilah "kematian bahasa" disebut juga dengan istilah language dissappear dan ada juga ahli yang menyebutnya dengan istilah language death. Sebagaimana ungkapan seorang pakar bahasa (Rogers: 1990:45) bahasa itu juga mengikuti siklus kehidupan; ada yang lahir, tumbuh, berkembang dan ada juga yang hilang (dissappear) atau bahkan mati. Secara prinsip kedua istilah tersebut sama. Di dalam bahasa Indonesia istilah kematian bahasa disebut juga dengan kepunahan bahasa. Seperti apakah bahasa yang mati tersebut? Apa penyebab kematian bahasa? Di dalam tulisan ini akan dibahas seluk-beluk kematian bahasa dan apa saja faktor-faktor yang menyebabkan sebuah bahasa tersebut mati.

Kematian bahasa mengalami proses yang membutuhkan waktu yang panjang. Tidak ada peristiwa dimana sebuah bahasa langsung mati begitu saja. Sebelum matinya sebuah bahasa ada juga masa "sakarat" atau hampir-hampir punah (endanger). British Library (1999: 20) ..."salah satu upaya untuk menyelamatkan warisan budaya yang hampir punah termasuk di dalamnya bahasa maka seluruh masyarakat dunia harus memiliki perhatian terhadap warisan tersebut". Apabila ada kemauan untuk menyelamatkan bahasa yang sakarat tersebut maka bahasa itu akan tetap lestari sehingga tidak jadi mati atau punah.

Beberapa faktor yang menyebabkan sakaratnya bahasa ini misalnya ketika sebuah bahasa dituturkan oleh hanya segelintir orang saja. Ada juga faktor lainnya yaitu tingkat harapan hidup masyarakat penuturnya sangat 
rendah sehingga proses alih generasinya tidak berlangsung lama.

Sebuah bahasa dikatakan mati apabila sebuah bahasa tidak ada lagi penuturnya. Menurut Groningen (1989: 37) bahwa ketika penutur sebuah bahasa tidak ada lagi maka bahasa itu dapat dikatakan mati. Dari dahulu sampai saat ini sudah ribuan banyaknya bahasa yang mati baik di Eropa, Afrika, Asia dan dan benua lain. Berbagai macam faktor menyebabkan sebuah bahasa punah sehingga tidak dapat dikenali lagi.

Di Indonesia ada beberapa bahasa daerah yang sudah sakarat yaitu di daerah pedalaman Irian Jaya atau Papua sekarang. Menurut hasil penelitian para ahli bahasa (Hasyim: 1998) dilaporkan bahwa setidaknya ada lebih kurang lima belas bahasa-bahasa daerah di pedalaman Papua yang sudah sakarat. Ada bahasa daerah di Papua yang penuturnya hanya dua keluarga saja. Tidak lebih dari lima belas orang saja. Menurut prediksi peneliti bahasa bahwa dalam jangka waktu sepuluh tahun ke depan bahasa ini sudah punah. Tinggal kenangan saja bagi kita orang Indonesia.

Hal ini seyogyanya menjadi perhatian yang serius oleh pemerintah hendaknya. Seandainya bahasa itu sudah mati sedangkan arsip yang tertulis tidak ada maka habislah bahasa tersebut untuk selamanya. Sebagaimana kata pakar bahasa Fishman (1980) jika sebuah bahasa mati maka butuh ribuan tahun lagi untuk menghidupkannya. Namun kalau arsip tertulis tentang sebuah bahasa yang mati itu tidak ada maka sangat susah dan mungkin suatu hal yang sangat mustahil untuk menghidupkannya lagi. Bahasa itu hanya akan menjadi catatan bagi sebuah peradaban manusia. Bahasa itu akan terkubur tanpa batu nisan yang jelas. Semua artefak bahasa akan menjadi objek wisata bagi manusia yang hidup sesudahnya.

\section{PENYEBAB KEMATIAN BAHASA}

Menurut para ahli bahasa ada beberapa penyebab kematian bahasa secara umum, yaitu:

\section{Bencana Alam}

Bencana alam seperti banjir besar, tsunami, tanah longsor dan letusan gunung api adalah faktor terbesar yang menyebabkan kematian sebuah bahasa. Bencana alam seperti tsunami bisa membunuh ratusan ribu bahkan jutaan orang dalam sekejap. Misalnya tsunami yang melanda Aceh pada akhir Desember 2004. Menurut data yang dirilis oleh pemerintah bahwa peristiwa tsunami di Aceh tersebut menelan korban sebanyak lebih kurang 200.000 orang yang tersebar di beberapa kabupaten dan kota di sepanjang pantai barat Aceh. Akibat kematian ratusan ribu orang tersebut maka banyak pula bahasa daerah dan dialek di kabupaten yang dilanda tsunami tersebut musnah.

Begitu juga peristiwa letusan gunung Krakatau pada tahun 1883. Letusan gunung Krakatau tersebut juga menimbulkan tsunami di sepanjang Pantai Utara pulau Jawa dan menelan korban lebih dari 100.000 orang. Banyak pula bahasa yang dan dialek yang punah sejalan dengan peristiwa tersebut.

Di zaman para nabi dan rasul terdahulu juga pernah terjadi bencana alam seperti banjir besar di zaman Nabi Nuh a.s. Menurut perkiraan peneliti sejarah sebagaimana yang dirilis oleh National Geographic Channel (2011) peristiwa banjir dan topan nabi Nuh menghabiskan dua pertiga penduduk yang ada pada saat itu. Andai saja bahasa dan dialek sudah beragam saat itu, sudah bisa dipastikan banyak bahasa dan dialek yang hilang karena peristiwa tersebut.

Bencana alam adalah sebuah misteri yang tidak bisa diprediksi datangnya. Sebagai masyarakat yang hidup di zaman modern kita hanya bisa bermain 
spekulasi angka atau ramalan kapan sebuah bencana tersebut akan datang. Tetapi tidak ada yang bisa memastikan kapan sebuah bencana tersebut muncul. Kita harus siap setiap waktu dengan resiko yang akan terjadi.

\section{Peperangan dan Pembersihan Etnis}

Peperangan adalah merupakan salah satu faktor yang menyebabkan matinya sebuah bahasa. Betapa tidak, sebuah peperangan sudah pasti menelan banyak korban jiwa. Bisa ratusan, ribuan bahkan jutaan nyawa melayang karena peperangan. Haroold (1978: 340) menyebutkan Perang dalam skala besar seperti Perang Dunia I dan Perang Dunia ke II menelan korban jutaan nyawa manusia. Perang tidak hanya membunuh manusia tetapi juga membunuh makhluk hidup lainnya, juga membunuh budaya, agama dan bahasa.

Seiring dengan matinya jutaan jiwa manusia tersebut maka punah pulalah bahasa yang mereka tuturkan. Begitu juga perang dalam skala menengah yang melibatkan dua negara saja seperti perang Irak dengan Iran pada tahun 1980 an. Perang antara Rusia dengan Afganistan (para pengamat memakai istilah penjajahan atau aneksasi) juga menelan korban ratusan ribu nyawa manusia. Ratusan ribu rakyat Afganistan meregang nyawa tanpa tahu apa salah mereka. Anak-anak, orang tua, wanita, orang jompo yang semestinya mendapat perlindungan dalam perang sebagaimana yang diatur oleh konvensi Genewa dibunuh dengan senjata modern. Mereka sendiri mungkin tidak pernah tahu mengapa negara mereka berperang. Begitu juga di zaman modern ini, bagaimana Amerika dan sekutunya yang bernaung di bawah bendera PBB dan NATO menggempur rakyat Afganistan. Yang mati disana tidak hanya manusia, tetapi juga bahasa dan budaya sebuah komunitas yang merupakan warisan dunia yang tak ternilai. Para pengamat hanya memprediksi berapa jumlah korban jiwa dan korban materi. Tidak pernah ada kalkulasi kerugian budaya, bahasa, seni dan nilai tradisi sebuah komunitas.

Ada pula perang dalam skala kecil yaitu antar kelompok atau suku dalam satu negara seperti perang berkepanjangan antara suku Hutu dan Tutsi di negara Rwanda di Afrika. Jutaan rakyat Rwanda tewas akibat peperangan yang tak berujung tersebut. Akibatnya, banyak pula bahasa dan dialek dalam suatu komunitas yang punah seiring dengan kematian manusia dalam peperangan tersebut. Perang saudara di Rwanda juga menghancurkan sendi-sendi budaya kedua suku tersebut.

Faktor yang hampir sama dengan peperangan yaitu Pembersihan Etnis (etnic clearance) yaitu pembunuhan secara massal terhadap satu kelompok atau komunitas tertentu oleh kelompok lain secara terencana. Kasus seperti ini sudah banyak terjadi misalnya pembersihan Etnis muslim di Bosnia, di Serbia dan negara-negara kecil pecahan Yugoslavia. Ada juga konflik yang diciptakan di Rusia yaitu pembersihan etnis Checnya atau orang-orang Cecen di pegunungan Kaukasus. Alasannya adalah menumpas para pemberontak padahal hal itu juga tak ada bedanya dengan pembersihan etnis Cecen yang notabene tidak memiliki paham yang sama dengan penguasa Rusia. Akibat dari punahnya satu etnis maka sudah bisa dipastikan mati pula bahasa dan dialek suatu etnis tersebut. Namun sampai saat ini etnis Cecen masih memberikan perlawanan terhadap Rusia. Mereka tetap berjuang demi etnis, tanah dan agama serta budaya mereka.

\section{Penyakit Menular}

Berbagai macam penyakit menular yang berbahaya dan mematikan pernah menyerang kelompok atau komunitas suatu bangsa. Misalnya wabah kolera di beberapa negara Afrika. Wabah penyakit Antrax, Cacar dan berbagai jenis 
penyakit menular lainnya. Dalam waktu yang sangat singkat, ribuan orang terkapar merenggut ajal. Akibatnya, banyak pula bahasa dan dialek tertentu yang punah karena tidak ada penutur suatu bahasa tersebut yang tertinggal.

Penyakit yang mematikan ini datangnya tidak mengenal waktu dan tempat. Dia bisa membunuh manusia, binatang dan tumbuh-tumbuhan kapan saja. Kita tidak bisa membayangkan andai kata satu daerah di Indonesia ini seperti Provinsi Sumatera Barat umpamanya dilanda wabah penyakit menular dan mematikan. Tentu akan punah bahasa Minang atau minimal dialek-dialek yang ada di Sumatera Barat.

Penyakit AIDS atau yang dikenal dengan istilah penyakit karena seks bebas yang menyebabkan daya tahan tubuh menurun secara drastis juga berpotensi membunuh bahasa. Andai saja di sebuah komunitas yang menganut seks bebas terjangkit penyakit AIDS maka dalam waktu cepat mereka akan mati dan seiring dengan kematian mereka secara kolektif maka bahasa mereka juga akan mati.

\section{Hegemoni Bahasa Asing}

Hegemoni atau dominasi yang kuat dari suatu bahasa terhadap suatu bahasa lain akan menyebabkan sebuah bahasa akan mati sebab sebagaimana hukum bahasa "survival of the fittest" yaitu bahasa yang kuat akan menguasai bahasa yang lemah. Hal ini juga tidak jauh bedanya dengan hukum rimba. Siapa yang berani dia yang menjadi raja. Yang tidak sanggup bertahan hidup akan dilindas oleh yang kuat.

Sebagai sebuah contoh bahasa Inggris. Menurut data UNESCO (2009) Saat ini setidaknya bahasa Inggris dituturkan oleh dua milyar orang di bumi ini. Padahal beberapa dekade yang lalu bahasa Inggris baru dituturkan oleh sekitar empat ratus juta orang saja. Perkembangannya sangat luar biasa. Dunia demam bahasa Inggris. Ada anggapan bahwa kalau tidak bisa berbahasa Inggris berarti belum maju.

Dalam kasus ini di beberapa negara bahwa sudah ada bahasa suatu negara yang sudah hampir mati karena kuatnya dominasi bahasa Inggris dalam negara tersebut. Andaikata penduduk suatu negara tersebut tidak memiliki sense of belonging terhadap bahasa negara mereka maka kematian bahasa mereka tinggal menunggu waktu saja. mengapa Bahasa Inggris begitu mendunia dan memiliki hegemoni yang kuat?

Alasan pertama adalah alasan sejarah. Bangsa Inggris adalah bangsa yang dikenal sebagai bangsa yang memiliki daerah jajahan terbanyak di dunia ini. Negara jajahan mereka disatukan dalam satu persemakmuran atau commonwealth state. Bangsa Inggris selalu mengajarkan bahasa mereka kepada rakyat di tanah jajahannya sehingga rakyat yang ada di daerah jajahan tersebut bisa berbahasa Ingsris.

Alasan kedua adalah pengaruh politik. Secara politik dunia semenjak berakhirnya Perang Dunia II maka negara yang menguasai dunia adalah dua negara super power atau negara adikuasa yaitu Amerika Serikat dan Uni Soviet atau Rusia sekarang. Namun pada tahun 1990 an negara Uni Soviet hancur berkeping-keping sehingga menjadi negara-negara kecil. Semenjak kehancuran Uni Soviet itu dominasi politik dunia tinggal satu lagi yaitu Amerika Serikat. Kalau kita lihat sejarahnya bangsa Amerika kebanyakan adalah imigran dari Eropa dan mereka berbahasa Inggris. Nenek moyang orang Amerika kulit putih banyak yang keturunan bangsa Inggris.

Karena mereka "menguasai" dunia maka segala yang mereka buat tentu dipengaruhi oleh bahasa dan budaya mereka. Dalam hal bahasa mereka memakai bahasa Inggris. Sudah pasti orang lain yang butuh dengan Amerika harus 
belajar bahasa Inggris. Ditambah lagi dengan kepedulian pemerintah mereka terhadap politik bahasa mereka yang sangat tinggi. Mereka menjadikan bahasa Inggris sebagai salah satu bahasa untuk komunikasi dunia internasional. Meskipun ada bahasa lain yang dipakai di dunia seperti baha Perancis, Spanyol, Arab, Jerman dan Rusia tetapi dominasi bahasa tersebut tidak sekuat dominasi bahasa Inggris.

Kita ambil contoh saja untuk urusan pendidikan. Pemerintah Amerika mewajibkan setiap orang yang akan bersekolah di Amerika bisa berbahasa Inggris dan dibuktikan dengan skor TOEFL yang bervariasi, misalnya untuk pendidikan Master (S2) dipatok angka 500 dan untuk Doktor (S3) dipatok skor 550. Untuk mendapatkan skor TOEFL yang di atas 500 tersebut tentu mereka harus belajar bahasa Inggris.

Dengan segala fasilitas dan kemewahan yang dijanjikan oleh Amerika tersebut maka berlomba-lomba lah orang dari seluruh dunia untuk belajar bahasa Inggris dan malah sampai lupa untuk belajar bahasa sendiri. Apabila kita sudah tidak memiliki rasa bangga dengan bahasa sendiri tentu lambat laun bahasa kita sendiri akan semakin terpinggirkan. Lama kelamaan bahasa kita juga akan mati.

\section{Perasaan Gengsi terhadap Bahasa Sendiri}

Perasaan gengsi, malu atau kurang percaya diri dari suatu kelompok penutur bahasa terhadap bahasa mereka sendiri bisa mengakibatkan kepunahan suatu bahasa. Mungkin gejala ini tidak akan terasa dalam waktu yang dekat, tetapi bisa dibuktikan dalam waktu yang cukup lama. Dalam hal ini penutur bahasa pada suatu kelompok bahasa tertentu cenderung menggunakan bahasa yang bukan bahasa mereka tetapi dipakai dalam komunikasi formal. Hari demi hari penutur bahasa tersebut akan mengalami gejala euforia menggunakan bahasa asing. Maka dapat dipastikan bahasa asli mereka akan semakin pudar dan rasa memiliki terhadap bahasa mereka semakin habis.

Contohnya, sekelompok masyarakat penutur bahasa Minang dalam suatu daerah yang lebih maju akan cenderung berbahasa Indonesia dan sering menggunakan istilah-istilah bahasa Inggris dalam komunikasi mereka. Tentu saja mereka merasa bangga dengan menggunakan bahasa asing karena dianggap memiliki gengsi yang lebih tinggi. Mereka juga merasa bahwa dengan menggunakan bahasa asing tersebut status sosial mereka semakin terangkat. Mereka merasa lebih intelek atau merasa golongan "atas" kalau berbahasa Inggris. Andaikata "penyakit" ini melanda suatu kelompok penutur bahasa maka perlahan-lahan bahasa asli mereka akan terpinggirkan. Bahkan tidak sedikit orang yang tidak mampu menggunakan bahasa asli mereka dan tidak sedikit pula yang tidak mengenal sama sekali bahasa leluhur mereka.

\section{Migrasi}

Migrasi atau perpindahan suatu kelompok penutur bahasa ke daerah lain yang memiliki bahasa yang berbeda dapat mengakibatkan kepunahan bahasa. Apalagi kalau masyarakat yang berpindah itu bagaikan kacang lupa dengan kulitnya. Contoh kasus dalam hal ini adalah kebiasaan merantau ke daerah yang berbeda bahasa, transmigrasi dan sebagainya.

Misalnya satu keluarga keturunan Minang menggunakan dialek Minang X. Penutur dialek $X$ ini hanya beberapa keluarga saja. Untuk berjuang hidup mereka merantau ke Jakarta umpamanya. Di Jakarta mereka akan menggunakan bahasa Indonesia dalam berkomunikasi sehari-hari karena bahasa Indonesia adalah bahasa yang dipakai dalam komunikasi sehari-hari. 
Lambat laun, anak keturunan mereka yang lahir di perantauan tersebut akan berbahasa Indonesia dalam keluarganya apalagi kalau orang tua mereka tidak pernah mengajarkan bahasa asli mereka kepada keturunannya. Bisa kita bayangkan apa akibatnya pada keturunan mereka berikutnya. Bisa kita pastikan bahwa anak keturunan mereka tidak akan bisa berbahasa mereka karena mereka tidak dikenalkan dengan bahasa leluhur mereka. Fenomena seperti ini juga merupakan salah satu faktor yang dapat membunuh bahasa.

Begitu juga halnya dengan transmigrasi. Sebagai contoh, pada tahun 1970an pemerintah saat itu membuat kebijakan transmigrasi penduduk dari beberapa daerah di Pulau Jawa ke daerah-daerah yang ada di Indonesia. Di Sumatera Barat misalnya, mereka ditempatkan di daerah Sitiung di kabupaten Darmasraya sekarang. Bagi mereka yang transmigrasi satu kampung dan satu dialek dari Jawa sana maka mereka akan menggunakan bahasa Jawa antar sesama mereka tetapi mereka terpaksa menggunakan bahasa Minang berdialek Sitiung yang ada di daerah itu. Andai kata pengaruh atau dominasi bahasa Minang berdialek Sitiung lebih kuat dibanding bahasa Jawa di daerah tersebut maka lama kelamaan penutur bahasa Jawa yang ada di daerah Sitiung itu akan terbiasa menggunakan bahasa Minang berdialek Sitiung. Proses ini dimulai dengan pemahaman, pengucapan dan pencampur bauran bahasa.

Akibatnya, muncullah bahasa Minang berdialek Jawa. Tetapi jika dominasi bahasa Jawa yang lebih kuat maka bahasa Minang berdialek Sitiung yang akan mengalah. Tidak tertutup kemungkinan bahwa transmigrasi juga akan menimbulkan lahirnya bahasa baru atau dikenal dengan istilah Pidgin. Penutur yang sama-sama tidak paham bahasa masing-masing akan menggunakan istilah baru untuk berkomunikasi.
Apabila istilah ini sudah merakyat maka istilah yang sudah ada dalam bahasa asli kita akan hilang. Apabila suku kata semakin hari berangsur hilang atau berganti maka ini adalah pertanda bahwa pada suatu saat bahasa itu akan mati.

Namun proses alam sering menunjukkan bahwa sesuatu yang datang lebih cenderung mengalah meskipun pada kasus tertentu ada pendatang yang lebih dominan. Pendatang banyak berkuasa dibanding pribumi apalagi kalau pendatang sudah menguasai sektor-sektor yang penting dalam kehidupan seperti ekonomi, pemerintahan, politik, perdagangan, pertambangan dan berbagai sektor lainnya. Secara perlahan tapi pasti, segala yang berbau pribumi akan tersingkir dan hilang ditelan zaman.

\section{Kebijakan Politik}

Kebijakan politik yang tidak seimbang atau lebih ekstrem terhadap suatu bahasa dari suatu pemerintahan juga berdampak negatif terhadap pemerintahanan bahasa. Contohnya, di beberapa negara di Eropa ada kebijakan politik yang pernah diterapkan oleh pemerintah Inggris terhadap masyarakat penutur bahasa Inggris berdialek Wales, Scotlandia dan Irlandia. Pemerintah melarang penggunaan bahasa Inggris yang berdialek selain London. Karena kekuatan penguasa tersebut terpaksalah penutur dialek bahasa selain London merubah dialek mereka kedalam dialek bahasa penguasa.

Akibatnya, perlahan-lahan dialek yang dilarang tersebut mati suri dan bahkan punah ditelan kebijakan politik yang ekstrem tersebut. Untung saja ada perubahan kebijakan politik dari generasi berikutnya sehingga memunculkan lagi kebebasan dalam menggunakan bahasa dan dialek.

Contoh lain, pernah juga di Amerika ketika awal abad 18 pemerintah yang berkuasa melarang penggunaan bahasa Indian di Amerika. Komunitas 
Indian yang ada pada saat itu terpaksa beralih bahasa ke bahasa Inggris kalau mereka ingin berkomunikasi dengan masyarakat keturunan Eropa. Orang Indian yang masih mengunakan bahasa Indian tidak dilayani dalam urusan pemerintahan, perdagangan dan kegiatan sosial lainnya.

Pada saa itu orang Indian suka atau tidak suka harus belajar bahasa Inggris. Akibatnya bahasa asli mereka terpinggirkan dan habis perlahan-lahan seiring dengan perkembangan zaman. Bahasa Indian tidak mendapatkan perhatian yang menarik dari pemerintah. Tidak ada upaya pelestarian bahasa asli Indian. Orang Indian dipaksa meninggalkan bahasa mereka dan beralih ke bahasa Inggris. Orang kulit hitam dan keturunan Indian adalah warga negara kelas dua, termasuk bahasa mereka.

\section{Perkawinan Campur / Silang}

Faktor lain yang menyebabkan matinya sebuah bahasa adalah kawin silang antar budaya. Trend warga negara kita kawin dengan bule yang melanda Indonesia beberapa tahun belakangan ini dapat juga mematikan sebuah bahasa asli kita. Apabila seorang warga negara kita kawin dengan orang asing dan tinggal di negara asing maka bahasa yang lebih dominan dipakai adalah bahasa suami mereka. Misalnya, kalau seorang perempuan Indonesia kawin dengan orang Jerman dan dibawa hidup ke Jerman, maka mereka akan berkomunikasi dalam bahasa Jerman. Lambat laun kelaurga mereka tidak akan mengenal bahasa Indonesia sehingga ketika suatu saat mereka berkunjung ke Indonesia mereka kesulitan berbahasa Indonesia. Tidak sedikit warga kita yang terpatah-patah berbahasa Indonesia karena lama hidup di luar negeri.

Akibatnya adalah bahasa asli yang sudah kita peroleh akan hilang perlahanlahan. Kita tidak akan mengenal budaya kita sendiri. Kalau saja kasus kawin silang antar budaya ini hanya terjadi satu atau dua orang saja tentu tidak akan berbahaya terhadap bahasa. Bagaimana kalau kawin silang itu terjadi pada sebagaian besar komunitas? Ratusan, ribuan bahkan puluhan ribu warga kita kawin dengan warga asing? Tentu saja sudah ada penutur bahasa yang berkurang.

\section{PENUTUP}

Dari uraian tersebut di atas dapat kita simpulkan bahwa setidaknya ada delapan faktor penyebab kematian bahasa. Faktor tersebut adalah: bencana alam, peperangan dan pembersihan etnis, penyakit menular, hegemoni bahasa asing, perasaan minder terhadap bahasa sendiri, migrasi, kebijakan politik dan kawin silang. Sebagai orang yang cinta akan budaya kita sendiri tentu kita wajib melestarikannya sampai kapanpun. Kalau kita tidak menginginkan bahasa kita mati atau sakarat semuanya terpulang kepada kita semua untuk memeliharanya. Tidak ada larangan bagi kita untuk belajar bahasa asing apa saja asalkan bahasa kita sendiri tidak terlupakan.

Harapan kita semua adalah agar tidak ada lagi bahasa yang mati. Kita pelihara apa yang sudah ada. Beragam cara kita lakukan demi pemertahanan bahasa kita. Akhir-akhir ini usaha yang dilakukan oleh sebuah badan PBB yaitu UNESCO untuk memelihara warisan budaya dunia patut kita acungi jempol. Masyarakat internasional sudah sepakat bahwa setiap bangsa yang ada di dunia ini wajib memelihara kelangsungan hidup budaya mereka sendiri.

Sebagai orang bahasa tentu kita lebih giat hendaknya untuk melakukan upaya-upaya pelestarian dan pemertahanan bahasa dalam rangka melindungi bahasa dari kematian. Andai saja ada bahasa yang sakarat sekarang ini di wilayah Indonesia maka hal tersebut adalah tugas kita untuk merawatnya agar tidak jadi mati, minimal dengan usaha pendataan kosa kata, dialek dan seluk bahasa tersebut selagi penuturnya ada. 


\section{DAFTAR RUJUKAN}

Baepler, Paul. (2003). "White slaves, African masters". The ANNALS of the American Academy of Political and Social Science. Cambridge: Cambridge University Press.

Barzilai, Gad. (2003). Communities and Law: Politics and Cultures of Legahkjkjl Identities. University of Michigan Press.

Bloomfield, Leonard (1974). revised edition. An introduction to the study of language. New York: Henry Holt and Company.

British Library. (1999). Endanger: Save the World. Birmingham. Christian Church Company.

Crystal, David (1997). The Cambridge Encyclopedia of Language. Cambridge: Cambridge University Press.

Crystal, David (2001). The Cambridge Encyclopedia of the English Language. Cambridge: Cambridge University Press.

Deddy Mulyana dan Jalaluddin Rakhmat. Komunikasi Antar budaya: Panduan Berkomunikasi dengan Orang-Orang Berbeda Budaya. 2006. Bandung: Remaja Rosdakarya.

Departemen Pendidikan dan Kebudayaan. (1999). Kamus Besar Bahasa Indonesia. Jakarta, Balai Pustaka.
Eugene, Joan. C. (2008). Language Dissappear. Journal of Language. Hongkong.

Freedman. A. (2003). Language Death. Language Research Project. Ontario: Ride Publishing.

Gleitman, Lila (1993) "A human universal: the capacity to learn a language." Modern Philology. New York: Longman.

Harimurti Kridalaksana (2008). Kamus Linguistik (edisi keempat). Jakarta: Gramedia Pustaka Utama.

Haroold. K.J. 1978. World War. Madison. Scotland F.A

Hasyim. A.B. 1998. Bahasa-Bahasa Nusantara. Solo. Dana Mitra

Katzner, K (1999). The Languages of the World. New York: Routledge.

Niedzielski, Nancy \& Dennis Preston (2000). Folk Linguistics. Berlin: Mouton de Gruyter.

Poedjosoedarmo, S. (2001). Filsafat Bahasa. Muhammadiyah University Press. Surakarta.

Rogers. T.S. (1990). Who Can Live? Essex. Roulede Printing.

UNESCO. http/www.unesco.org. retrived on march 2011.

Wardaugh, Ronald. (1983). An Introduction to Sociolinguistics. New York. McGrawHill Company.

faktor, 1, 128, 129, 132, 133

kematian, 1, 128, 130, 133, 134
Indeks

bahasa, 1, 128, 129, 130, 131, 132, 133, 134 

